\title{
Superior efficacy of Adalimumab in treating childhood refractory chronic uveitis when used as first biologic
}

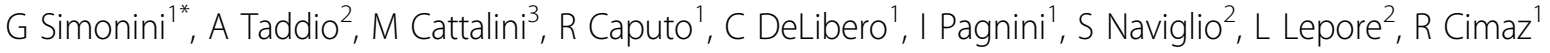 \\ From 18th Pediatric Rheumatology European Society (PReS) Congress \\ Bruges, Belgium. 14-18 September 2011
}

\section{Background}

We previously reported that Adalimumab is more efficacious than Infliximab in maintaining remission of chronic childhood uveitis.

\section{Aim}

To compare the efficacy of Adalimumab when used as first anti-TNF $\alpha$ therapy versus Adalimumab used after the failure of a previous anti-TNF $\alpha$ (Infliximab). Openlabel, comparative, multi-centre, cohort study of childhood non-infectious chronic uveitis.

\section{Methods}

26 patients (14 F, $12 \mathrm{M}$; median age: 8.6 years) with refractory, vision threatening, non-infectious active uveitis were enrolled. Due to the refractory course of uveitis to previous DMARD treatment, Group 1 received Adalimumab (24 mg/sq mt, every 2 weeks), as first antiTNF $\alpha$ choice; Group 2 received Adalimumab, as second anti-TNF $\alpha$ drug, due to the loss of efficacy of Infliximab, after a period of at least 1 year $(5 \mathrm{mg} / \mathrm{kg}$ at weeks $0,2,6$ and then every $6-8$ weeks). Both groups received Adalimumab for at least 1 year of treatment. Primary outcome was, once remission was achieved, the time to a first relapse. Time to achieve remission, and time to systemic corticosteroid discontinuation were also considered.

\section{Results}

14 children (10 with JIA, 3 with idiopathic uveitis, 1 with Behçet's disease) were recruited in Group 1; 12 children ( 7 with JIA, 3 with idiopathic uveitis, 1 with

\footnotetext{
* Correspondence: gabriele.simonini@unifi.it

${ }^{1}$ Anna Meyer Children's Hospital and University of Florence, Florence, Italy Full list of author information is available at the end of the article
}

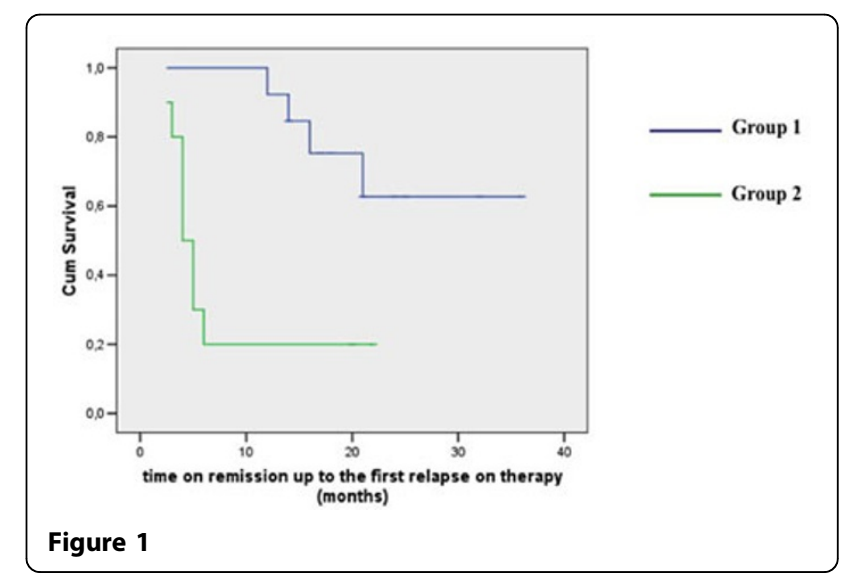

early-onset sarcoidosis, 1 with Behçet's disease) in Group 2. Cox-regression analysis did not show statistical significant differences between the two groups with regard to time to achieve remission, whilst Group 2 needed a longer time to discontinuation steroid (median \pm SE: $7 \pm 1.7$ vs $3 \pm 0.9$ months, CI 95\%: 3.6-10.4 vs 1.1$4.8, \mathrm{p}<0.001)$ and a lower probability to steroid discontinuation during the first 12 months of treatment (Mantel-Cox $\chi 2$ 4.12, $\mathrm{p}<0.041)$. In long-term follow-up, Group 1 had higher probability of uveitis remission (time to first flare) than Group 2 during the time of treatment on Adalimumab (median \pm SE: $18 \pm 1.1$ vs 4 \pm 0.6 months, CI 95\%: 15.6-27.5 vs 2.7-5.2, Mantel-Cox $\chi 2$ 10.1, $\mathrm{p}<0.002$ ) (Figure 1).

\section{Conclusions}

Even if limited to a relatively small group, our study suggests a better efficacy of Adalimumab when used as first anti-TNF $\alpha$ treatment in chronic childhood uveitis. 


\section{Author details}

${ }^{1}$ Anna Meyer Children's Hospital and University of Florence, Florence, Italy.

${ }^{2}$ Institute of Child Health, IRCCS Burlo Garofolo, University of Trieste, Trieste,

Italy. ${ }^{3}$ Pediatric Clinic, University of Brescia, Brescia, Italy.

Published: 14 September 2011

doi:10.1186/1546-0096-9-S1-P220

Cite this article as: Simonini et al:: Superior efficacy of Adalimumab in

treating childhood refractory chronic uveitis when used as first biologic.

Pediatric Rheumatology 2011 9(Suppl 1):P220.

Submit your next manuscript to BioMed Central and take full advantage of:

- Convenient online submission

- Thorough peer review

- No space constraints or color figure charges

- Immediate publication on acceptance

- Inclusion in PubMed, CAS, Scopus and Google Scholar

- Research which is freely available for redistribution

Submit your manuscript at 